\title{
Chronic Treatment with a Promnesiant GABA-A $\alpha 5$-Selective Inverse Agonist Increases Immediate Early Genes Expression during Memory Processing in Mice and Rectifies Their Expression Levels in a Down Syndrome Mouse Model
}

\author{
J. Braudeau, ${ }^{1}$ L. Dauphinot, ${ }^{1}$ A. Duchon, ${ }^{2}$ A. Loistron, ${ }^{1}$ R. H. Dodd, ${ }^{3}$ Y. Hérault, ${ }^{2,4}$ \\ B. Delatour, ${ }^{1}$ and M. C. Potier ${ }^{1}$ \\ ${ }^{1}$ Centre de Recherche de l'Institut du Cerveau et de Moelle Epinière, INSERM UMRS 975, CNRS UMR7225, UPMC, \\ 75013 Paris, France \\ ${ }^{2}$ Institut de Génétique et de Biologie Moléculaire et Cellulaire (IGBMC), Institut National de Santé et de Recherche Médicale (INSERM) \\ U964/Centre National de Recherche Scientifique (CNRS) UMR 1704/Université de Strasbourg, 67404 Illkirch, France \\ ${ }^{3}$ Institut de Chimie des Substances Naturelles-CNRS UPR 2301, 91198 Gif-sur-Yvette, France \\ ${ }^{4}$ Groupe d'Intérêt Economique-Centre Européen de Recherche en Biologie et en Médecine (GIE-CERBM), Institut Clinique de la Souris \\ (ICS), Université de Strasbourg, 67404 Illkirch, France
}

Correspondence should be addressed to M. C. Potier, marie-claude.potier@upmc.fr

Received 6 April 2011; Revised 27 July 2011; Accepted 31 July 2011

Academic Editor: Naheed R. Mirza

Copyright (c) $2011 \mathrm{~J}$. Braudeau et al. This is an open access article distributed under the Creative Commons Attribution License, which permits unrestricted use, distribution, and reproduction in any medium, provided the original work is properly cited.

Decrease of GABAergic transmission has been proposed to improve memory functions. Indeed, inverse agonists selective for $\alpha 5$ GABA-A-benzodiazepine receptors ( $\alpha 5 \mathrm{IA}$ ) have promnesiant activity. Interestingly, we have recently shown that $\alpha 5 \mathrm{IA}$ can rescue cognitive deficits in Ts65Dn mice, a Down syndrome mouse model with altered GABAergic transmission. Here, we studied the impact of chronic treatment with $\alpha 5$ IA on gene expression in the hippocampus of Ts65Dn and control euploid mice after being trained in the Morris water maze task. In euploid mice, chronic treatment with $\alpha$ IA increased IEGs expression, particularly of $c$-Fos and Arc genes. In Ts65Dn mice, deficits of IEGs activation were completely rescued after treatment with $\alpha 5 \mathrm{IA}$. In addition, normalization of Sod1 overexpression in Ts65Dn mice after $\alpha 5$ IA treatment was observed. IEG expression regulation after $\alpha 5$ IA treatment following behavioral stimulation could be a contributing factor for both the general promnesiant activity of $\alpha 5$ IA and its rescuing effect in Ts65Dn mice alongside signaling cascades that are critical for memory consolidation and cognition.

\section{Introduction}

Down syndrome (DS) affects $0.45 \%$ of human conceptions [1] and is the first cause of mental retardation. This disorder is induced by total or partial trisomy of human chromosome 21 (HSA21) that delays both physical and mental development of affected children. In particular, cognitive skills, including learning and memory functions, are severely impaired in DS subjects.

Although being the focus of intense research activity $[2,3]$, attempts at developing treatments for counteracting cognitive defects in DS patients have not yet been successful.
Since fifteen years, DS animal models have been engineered to mimic DS physiopathogeny. Ts65Dn mice [4], one of the most studied DS models, have 167 three-copy genes corresponding to more than half of the genes from HSA21. These mice develop gradual learning and memory impairments when compared to euploid animals (for review, see [5]) in conjunction with morphological anomalies. In addition, Ts65Dn mice show abnormal synaptic plasticity as exemplified by long-term potentiation (LTP) deficits [6].

Data from recent years strongly suggest that changes in LTP and associated learning and memory function in DS mice might result from an imbalance between excitatory and 
inhibitory neurotransmission. More precisely, it has been demonstrated that increased GABAergic activity in the brain of Ts65Dn mice could be responsible for altered cognitive phenotypes $[7,8]$, opening new avenues for therapeutic opportunities. Treatments relying on GABA-A antagonists such as picrotoxin and pentylenetetrazole (PTZ) have indeed rescued deficits in DS mice; GABA-A antagonists can restore normal LTP [8] and also normalize cognitive phenotypes in learning tests such as the novel object recognition [9] and Morris water maze [10]. Altogether, these studies suggest the potential use of GABA antagonists for stimulating cognitive performances in DS subjects. However, it is known that such drugs also have convulsant effects which definitively preclude their use as cognitive enhancers in humans.

As an alternative to GABA-A antagonists, GABA-A inverse agonists such as $\beta$-carbolines acting at the benzodiazepine recognition site decrease the efficacy of GABAergic transmission and have promnesiant effects [11-14]. Their use in humans is, however, hampered by their convulsant/proconvulsant and anxiogenic side effects $[15,16]$.

It is nonetheless assumed that various pharmacological profiles can be obtained using ligands with specific affinities for the different $\alpha 1, \alpha 2, \alpha 3$, or $\alpha 5$ benzodiazepine receptor subtypes [17] that are unevenly distributed in the brain [18-20]. It is known that the $\alpha 5$ subunit-containing receptors are largely expressed in the hippocampus $[21,22]$, a brain region involved in learning and memory processes that is dysfunctional in DS individuals $[23,24]$. In mice, invalidation or mutation of the gene coding for the $\alpha 5$ subunit potentiate synaptic plasticity [25] and concurrently improve cognitive performances [25-27] without inducing anxiogenic or proconvulsant/convulsant side effects [28-32]. Recently, we demonstrated that acute and chronic treatment with an $\alpha 5$-selective inverse agonist, and referred to herein as compound $\alpha 5 \mathrm{IA}$, initially developed by Merck Sharp and Dohme Research Laboratories $[33,34]$ can restore cognitive deficits in a DS mouse model [35]. We further showed that following treatment with $\alpha 5 \mathrm{IA}$, the immediate early gene (IEG) product Fos is selectively increased in brain regions involved in learning and memory in control and DS mice [35].

In order to obtain insights into gene regulation pathways involved in the pharmacological effect of $\alpha 5 \mathrm{IA}$, we studied gene expression profiles in hippocampi of euploids and Ts65Dn mice behaviorally exposed to the Morris water maze (MWM) task, and treated or not with $\alpha 5 \mathrm{IA}$. We found that chronic treatment with $\alpha 5$ IA globally increases the expression of IEGs and in particular of $c$-Fos and Arc. These effects could be related to the memory-enhancing properties classically described for $\alpha 5$ IA [28-32].

In Down syndrome mice, we observed an abnormally low level of IEG induction after behavioral stimulation. In addition, some three-copy genes were significantly overexpressed, including Sod1 gene. Chronic treatment of Ts65Dn mice with $\alpha 5$ IA normalized the expression level of Sod1 and in parallel restored a physiological level of IEGs expression. This double-action mode can explain the rescuing effect observed following $\alpha 5$ IA treatment in DS mice.

\section{Material and Methods}

2.1. Animals. Male mice were produced at the Intragene resource center (TAAM, CNRS UPS44 Orléans, France) and bred on a mixed genetic background $\mathrm{B} 6 \mathrm{C} 3\langle\mathrm{~B}\rangle$, derived from C57BL/6J (B6) and a congenic inbred line $\mathrm{C} 3 \mathrm{H} / \mathrm{HeH}$ for the BALB/c wild-type Pde6b allele [36], thus avoiding retinal degeneration and impaired visual acuity. On this background, Ts65Dn mice showed similar behavioral phenotypes when compared to the original Ts65Dn line (AD and $\mathrm{YH}$, personal communication; see also [37]). Mice were acclimated in our animal facility for at least 2 weeks before initiating behavioral testing. All experiments were conducted in accordance with the ethical standards of French and European regulations (European Communities Council Directive of 24 November 1986). A total number of 24 mice (12 Ts65Dn and 12 euploid mice) were behaviorally trained in the MWM task. Only a subset of these animals (7 and 1011 mice per genotype for microarray and QPCR analysis, resp.) were processed for the molecular biology analysis described in the present work, (Figure 1).

2.2. $\alpha 5$ IA Synthesis and Formulation. The drug used is 3-(5methylisoxazol-3-yl)-6-(1-methyl-1,2,3-triazol-4-yl)methyloxy-1,2,4-triazolo[3,4-a]phthalazine ( $\alpha 5$ IA). It was synthesized by Orga-Link SARL (Magny-les-Hameaux, France), according to Sternfeld and collaborators [34]. The hydrochloride salt was prepared by dissolving the base in hot ethanol and adding a solution of 5\% hydrochloric acid in ethanol until the solution was slightly acidic. Upon cooling, a precipitate formed which was collected by filtration, washed with cold ethanol, and dried.

The $\mathrm{HCl}$ salt of $\alpha 5 \mathrm{IA}$ was solubilized in a mixture of DMSO, Cremophor El (BASF, Ludwigshafen, Germany), and hypotonic water (ProAmp) $(10: 15: 75)$. $\alpha 5$ IA or vehicle (solubilization solution) was injected intraperitoneally (i.p.) at $5 \mathrm{mg} / \mathrm{kg}[35]$.

2.3. Morris Water Maze. Cognitive stimulation was performed during 12 consecutive days in the MWM as previously described [35]. In brief, training consisted in a goallocation task in a pool (2-4 learning trials per daily sessions). Euploid and Ts65Dn mice were injected each day with either vehicle or $\alpha 5$ IA ( 6 mice per group), 30 min before starting the session. Distance travelled to find the platform has been used as learning index. We compared the performances of vehicletreated Ts65Dn mice to the 3 other groups ( $\alpha 5$ IA-treated Ts65Dn mice, vehicle-treated euploids, and $\alpha 5 \mathrm{IA}$-treated euploids) using Student's $t$-tests. Statistical significance was set to a $P$ value $<0.05$.

2.4. cRNA Probe Preparation and Hybridization. Twenty five min following the last MWM training session, animals were sacrificed, and their brains were extracted and processed for gene expression profiling. Total RNAs were obtained from frozen individual hippocampi and treated with DNAse using NucleoSpin RNA II kit (Macherey Nagel, France) in accordance with the manufacturer's protocol. The quality 


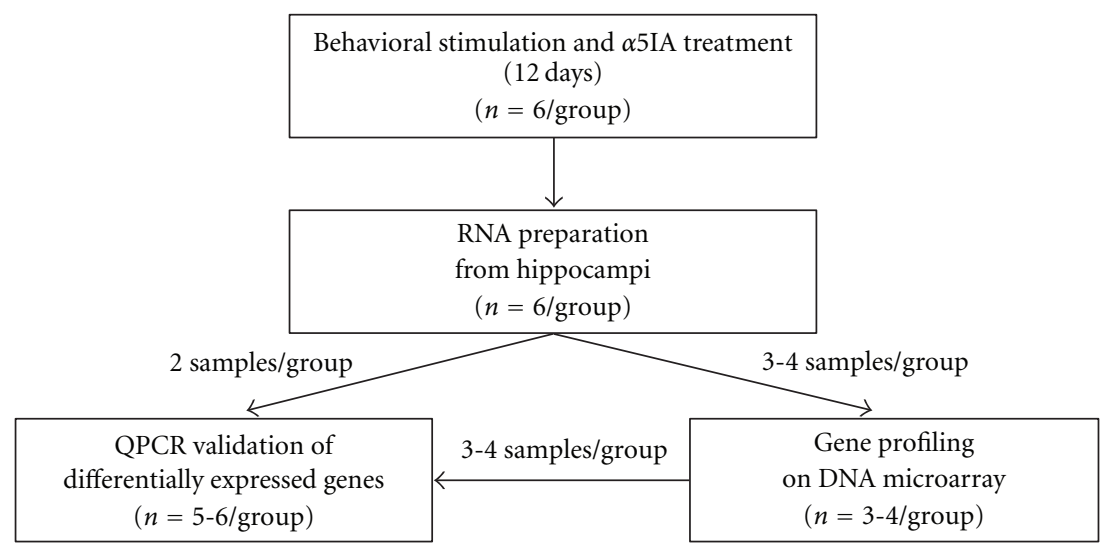

FIGURE 1: Experimental design used for the genomic studies: microarray and QPCR.

and quantity of each RNA preparation were assessed on the Agilent 2100 Bioanalyzer with RNA 6000 NanoChips (Agilent Technologies).

Hundred ng of each RNA were amplified and labelled with Cy3 using the Low Imput Quick Amp labeling kit (Agilent Technologies) according to the manufacturer's instructions. After purification and quantification on a Nanoview (ThermoFisher Scientific), $2 \mu \mathrm{g}$ of each Cy3cRNA were hybridized overnight on Whole Mouse Genome $4 \times 44 \mathrm{~K}$ v1 Microarrays (Agilent Technologies) according to the manufacturer's instructions.

2.5. Microarray Expression Data Analysis. Microarrays data were acquired on an Innoscan 900 (Innopsys, France) with a resolution of $2 \mu \mathrm{m}$ and analyzed with Mapix 5.0.0 software (Innopsys, France). For each array, raw data consisted of the median feature intensity and background feature intensity (F-B) at wavelength $532 \mathrm{~nm}$. These raw data were $\log 2$ transformed and quantile normalized under the R freeware (http://www.r-project.org/). Analysis of variance (ANOVA) with two main factors, Genotype (Ts65Dn versus euploid) and Treatment ( $\alpha 5$ IA versus vehicle), was then performed on the normalized data using the software $\mathrm{MeV}$ 4.6.2 (http:// www.tm4.org/mev/). Gene ontology (GO) category enrichment analysis was realized using the web-based GOrilla application (http://cbl-gorilla.cs.technion.ac.il/). Statistical significance was set to a $P$ value $<0.05$.

2.6. Real-Time Quantitative PCR. RNAs from dissected hippocampi (500 ng) were individually reverse transcribed into cDNAs overnight at $37^{\circ} \mathrm{C}$ using the Verso cDNA kit (ThermoFisher Scientific, Waltham, USA) according to the manufacturer's instructions. qPCR assays were performed in a Lightcycler 480 System (Roche), in the presence of $200 \mathrm{nM}$ of each primer: (c-Fos 5'agggagctgacagatacactcc3' forward and 5'tgcaacgcagacttctcatc3' _reverse; Homer1 5 'gatggagctgaccagtaccc $3^{\prime}$ _forward and 5 'tggtgtcaaaggagactgaaga $3^{\prime}$ _reverse; Ifnar2 5 'ggacagcgttaggaagaagc $3{ }^{\prime}$ forward and 5'tggaagtaagtctctaaggacaaatg $3^{\prime}$ _reverse; Egr $25^{\prime}$ ctacccggtggaagacctc $3^{\prime}$ _forward and 5 'aatgttgatcatgccatctcc $3^{\prime}$ _reverse;
$B d n f$ 5'agtctccaggacagcaaagc $3^{\prime}$ forward and 5'tgcaaccgaagtatgaaataacc $3^{\prime}$ _reverse; Arc 5'ggtgagctgaagccacaaat3' forward and $5^{\prime}$ ttcactggtatgaatcactgctg $3^{\prime}$ _reverse; Sod $15^{\prime}$ caggacctcattttaatcctcac $3^{\prime}$ _forward and $5^{\prime}$ tgcccaggtctccaacat $3^{\prime}$ _reverse; pPib $5^{\prime}$ ttcttcataaccacagtcaagacc $3^{\prime}$ _forward and 5'accttccgtaccacatccat $3^{\prime}$ reverse for normalization), $100 \mathrm{nM}$ of specific hydrolysis probe (designed with Universal Probe Library, Roche Applied Science) and 1X Lightcycler 480 Probes Master mix (Roche, France) and normalized using the Lightcycler 480 SW 1.5 software. Data were analyzed using an analysis of variance (ANOVA) with two main factors: genotype (Ts65Dn versus euploid) and treatment ( $\alpha 5$ IA versus vehicle), and Fisher's post hoc complementary analysis was carried out when required by the experimental design to assess complementary statistical effects. Pearson correlation coefficients between IEGs expression and behavioral data (mean distance travelled during the first three days trial of the MWM task) were calculated. All analyses were performed using Statistica v6 (StatSoft, Inc., Tulsa, Okla, USA) or GraphPad Prism (GraphPad Software, La Jolla, Calif, USA) softwares. Statistical significance was set to a $P$ value $<0.05$.

\section{Results}

3.1. Gene Expression Profiles after Treatment with $\alpha 5 I A$ in Euploid and Ts65Dn Mice Hippocampi. We showed previously that Ts65Dn mice are impaired in the MWM task and that their learning proficiency can be restored following $\alpha 5 \mathrm{IA}$ treatment [35]. In the present study, mice were trained in the MWM task using a similar protocol and treated daily with $\alpha 5 \mathrm{IA}(5 \mathrm{mg} / \mathrm{kg})$. Behavioral data were analyzed although the number of animals was small (5 or 6 per group) and precluded any robust statistical analysis (ANOVA). During the three first training sessions, vehicle-treated Ts65Dn mice travelled a longer distance to find the platform as compared to $\alpha 5$ IA-treated Ts65Dn mice or euploid mice treated with vehicle or $\alpha 5$ IA $\left(t_{16}=7.23 ; P=.016\right.$; Figure 2$)$. Thus, as previously described in [35], we showed that behavioral deficit of the Ts54Dn mice in the MWM task was recovered following $\alpha 5$ IA treatment. Twenty five minutes after completion of this long-term behavioral stimulation (12 days), 
TABLE 1: Analysis of variance (ANOVA) of microarray data: genotype (Euploids versus Ts65Dn mice) and treatment (Vehicle versus $\alpha 5$ IAtreated) were the two main factors. Three-copy genes and IEGs were analyzed separately.

\begin{tabular}{|c|c|c|c|c|}
\hline & \multirow[b]{2}{*}{ Total } & \multicolumn{3}{|c|}{ Analysis of variance (ANOVA) of microarray data } \\
\hline & & Genotype-modulated genes & Treatment-modulated genes & Interaction-modulated genes \\
\hline All genes & 13024 & 848 & 781 & 1260 \\
\hline \multirow{2}{*}{$3 \mathrm{~N}$ genes } & 56 & 6 & 3 & 5 \\
\hline & Genes & $\begin{array}{c}\text { GART, Ifnar-2, Kcnj6, Itsn1, Hlcs, and } \\
\text { Sod1 }\end{array}$ & App, Kcnj6, and Sod1 & $\begin{array}{c}\text { Cbr1, Gabpa, 4931408A02Rik, } \\
\text { Hmngn1, and Pcp4 }\end{array}$ \\
\hline \multirow{2}{*}{ IEGs and $B D N F$} & 16 & $5(* * *)$ & $3(*)$ & 1 \\
\hline & Genes & BDNF, Cox2, Homer1, GS2, and Arc & Fos, Egr2, and BDNF & $B D N F$ \\
\hline
\end{tabular}

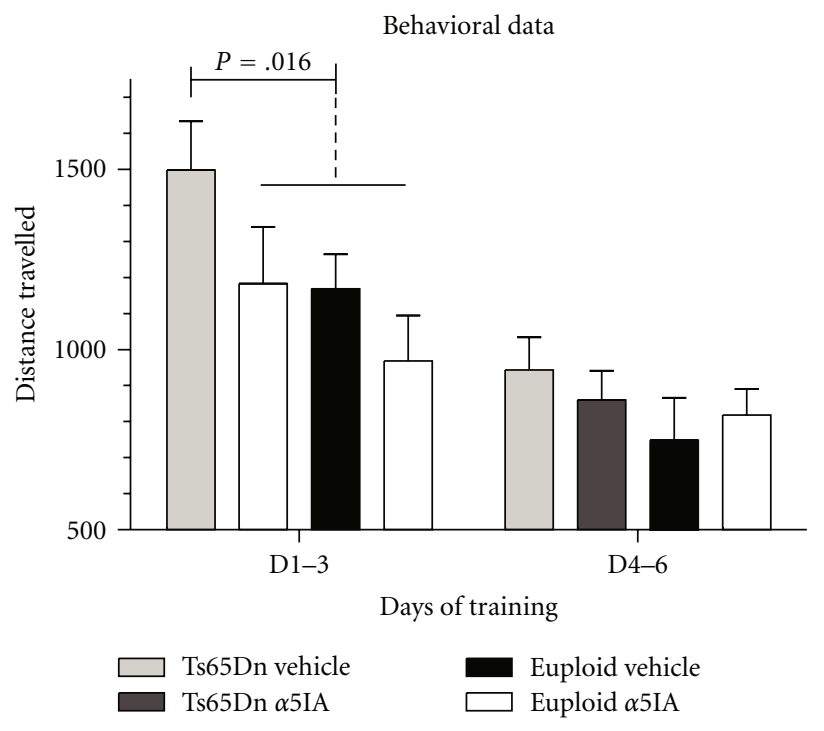

Figure 2: Effects of $\alpha 5$ IA treatment in Ts65Dn mice trained in the MWM task. TS65Dn mice had impaired performance in the MWM task (comparison with other groups: $P<.025$ ). This deficit was rescued by treatment with $\alpha 5$ IA.

mice were sacrificed and their hippocampi dissected. RNAs were extracted and amplified, labeled using in vitro transcription, and then hybridized on microarrays.

Among 41,000 genes present on the microarray, 13,024 were found to be expressed. Data were normalized and analyzed using ANOVA with two factors: genotype and treatment (Table 1). We found an effect of genotype (euploid versus Ts65Dn) on 848 genes representing $4.52 \%$ of whole genes expressed, an effect of treatment (vehicle versus $\alpha 5 \mathrm{IA}$ $5 \mathrm{mg} / \mathrm{kg}$ ) on 781 genes $(4.17 \%)$ and a genotype-treatment interaction effect on 1,260 genes (6.73\%). Principal component analysis (PCA) using all the genes expressed did not reveal any segregation of animal groups (data not shown), indicating that genotype and treatment did not globally affect expression profiles. Among the differentially expressed genes, we searched for enrichment of genes belonging to particular gene ontology (GO) categories. As shown in Table 2, 17 and 19 GO categories were significantly enriched among genes differentially expressed according to genotype and treatment, respectively. Eighteen of these GO categories were directly related to neurogenesis (Table 2 in bold).

We then analyzed the expression data focusing on genes of interest such as the expressed genes that are in three copies in Ts65Dn mice (3N genes, $n=56$ ) and immediate early genes (IEGs, $n=16$ ) which are involved in active memorization processes, and the product of which was shown to be increased by $\alpha 5$ IA treatment in a previous study [35].

3.2. Gene Expression Changes of $3 N$ Genes after $\alpha 5 I A$ Treatment. PCA on the $563 \mathrm{~N}$ genes expressed in hippocampus showed a partial segregation between euploid and Ts65Dn mice (Figure 3). Expression levels of 3N genes were significantly different in Ts65Dn mice as compared to euploid mice $(t$-test $P<.05)$ with a mean ratio of 1.13 and 1.10 between ts65Dn and euploid mice under vehicle or $\alpha 5$ IA treatment, respectively, suggesting a global increase of expression of three-copy genes. ANOVA with two factors (genotype and treatment) specifically on $3 \mathrm{~N}$ genes revealed an effect of genotype on 6 genes that represented 10.71\% of the total number of expressed triplicate genes (56): Gart, Ifnar-2, Kcnj6, Itsn1, Hlcs, and Sod1 (Table 1). The mean expression ratio Ts65Dn/Euploid for these 6 threecopy genes was found to be $1.22\left(t_{12}=3.49 ; P=.0045\right)$. In addition, we found that $\alpha 5$ IA treatment impacted on the expression levels of 3 three-copy genes (App, Kcnj6, and Sod1). Interactions between genotype and treatment were significant for 5 genes (Cbrl, Gabpa, 4931408A02Rik, Hmngn1, and Pcp4). Among differentially expressed genes, there was no significant enrichment of $3 \mathrm{~N}$ genes. However, a strong tendency to overrepresentation of three-copy genes modulated by the genotype factor in comparison to the overall distribution was observed (chi-square: $P=.057$; Table 1).

Among these genes modulated by the genotype factor, our attention was particularly drawn to the Sod1 gene whose role in DS was largely demonstrated $[38,39]$. In order to confirm the microarray results, QPCR analysis was performed on RNAs from 13 mice (3-4 per group) used for microarray and on RNAs from onther 8 mice (2 per group). Two-way ANOVA analysis on Sod1 gene showed a treatment by genotype interaction effect $\left(F_{1,17}=16.77 ; P<.00005\right.$; Figure 4). Sod1 expression level of vehicle-treated Ts65Dn mice increased in comparison to vehicle-treated mice 
TABLE 2: Analysis of GO categories among the genes differentially expressed in the hippocampus of Ts65Dn mice after $\alpha 5 \mathrm{IA}$ and behavioral stimulation. In bold GO categories related to neurogenesis processes.

\begin{tabular}{|c|c|c|}
\hline GO term & Description & $P$ value \\
\hline \multicolumn{3}{|c|}{$\begin{array}{l}\text { Enrichment analysis of GO biological processes associated with } \\
\text { genotype }\end{array}$} \\
\hline GO:0051272 & $\begin{array}{l}\text { Positive regulation of cellular } \\
\text { component movement }\end{array}$ & $2.93 E-4$ \\
\hline GO:0007216 & $\begin{array}{l}\text { Metabotropic glutamate receptor } \\
\text { signaling pathway }\end{array}$ & $2.96 E-4$ \\
\hline GO:0032879 & Regulation of localization & $3.3 E-4$ \\
\hline GO:0016265 & Death & $3.55 E-4$ \\
\hline GO:0009798 & Axis specification & $3.58 E-4$ \\
\hline GO:0006414 & Translational elongation & $3.77 E-4$ \\
\hline GO:0030335 & Positive regulation of cell migration & $4.21 E-4$ \\
\hline GO:2000147 & Positive regulation of cell motility & $4.21 E-4$ \\
\hline GO:0008219 & Cell death & $4.49 E-4$ \\
\hline GO:0065008 & Regulation of biological quality & $4.66 E-4$ \\
\hline GO:0012501 & Programmed cell death & $5.3 E-4$ \\
\hline GO:0008624 & $\begin{array}{l}\text { Induction of apoptosis by } \\
\text { extracellular signals }\end{array}$ & $5.44 E-4$ \\
\hline GO:0040017 & Positive regulation of locomotion & $7.32 E-4$ \\
\hline GO:0008283 & Cell proliferation & $7.77 E-4$ \\
\hline GO:0000578 & Embryonic axis specification & $7.96 E-4$ \\
\hline GO:0006916 & Antiapoptosis & $8.14 E-4$ \\
\hline GO:0007049 & Cell cycle & $9.3 E-4$ \\
\hline \multicolumn{3}{|c|}{$\begin{array}{l}\text { Enrichment analysis of GO biological processes associated with } \\
\alpha 5 \text { IA treatment }\end{array}$} \\
\hline GO:0046883 & Regulation of hormone secretion & $4.35 E-5$ \\
\hline GO:0030335 & Positive regulation of cell migration & $4.89 E-5$ \\
\hline GO:2000147 & Positive regulation of cell motility & $4.89 E-5$ \\
\hline GO:0040017 & Positive regulation of locomotion & $9.19 E-5$ \\
\hline GO:0051272 & $\begin{array}{l}\text { Positive regulation of cellular } \\
\text { component movement }\end{array}$ & $1.04 E-4$ \\
\hline GO:0048869 & Cellular developmental process & $1.49 E-4$ \\
\hline GO:0007176 & $\begin{array}{l}\text { Regulation of epidermal growth } \\
\text { factor receptor activity }\end{array}$ & $3.38 E-4$ \\
\hline GO:0040008 & Regulation of growth & $5.16 E-4$ \\
\hline GO:0051270 & $\begin{array}{l}\text { Regulation of cellular component } \\
\text { movement }\end{array}$ & $5.9 E-4$ \\
\hline GO:0000302 & Response to reactive oxygen species & $5.98 E-4$ \\
\hline GO:0030334 & Regulation of cell migration & $6.81 E-4$ \\
\hline GO:0048519 & $\begin{array}{l}\text { Negative regulation of biological } \\
\text { process }\end{array}$ & $7.57 E-4$ \\
\hline GO:0009888 & Tissue development & $8.46 E-4$ \\
\hline GO:0006012 & Galactose metabolic process & $9.12 E-4$ \\
\hline GO:0009896 & Positive regulation of catabolic process & $9.15 E-4$ \\
\hline GO:0030154 & Cell differentiation & $9.24 E-4$ \\
\hline GO:2000145 & Regulation of cell motility & $9.33 E-4$ \\
\hline GO:0035413 & $\begin{array}{l}\text { Positive regulation of catenin import } \\
\text { into nucleus }\end{array}$ & $9.67 E-4$ \\
\hline GO:0031331 & $\begin{array}{l}\text { Positive regulation of cellular catabolic } \\
\text { process }\end{array}$ & $9.98 E-4$ \\
\hline
\end{tabular}

$\left(F_{1,17}=7.01 ; P<.05\right)$ with a mean ratio of 1.27 (Figure 4$)$. Treatment reduced the level of Sod1 expression in $\alpha 5$ IA-

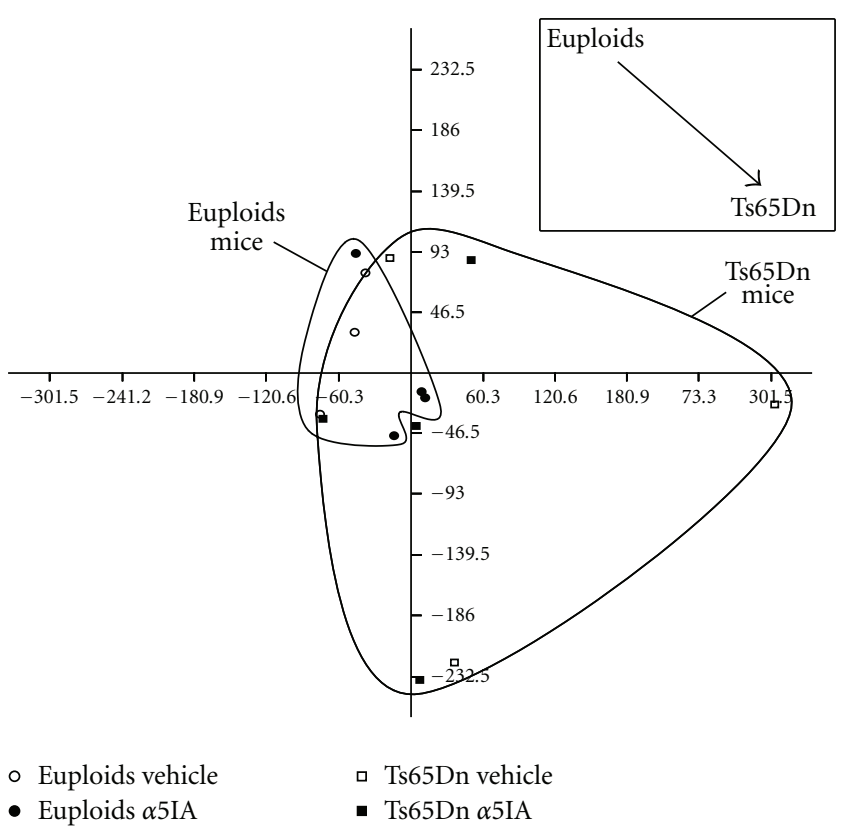

FIgURE 3: PCA on three-copy genes from Ts65Dn mice measured on microarrays. The first two principal components discriminated between euploid and Ts65Dn mice.

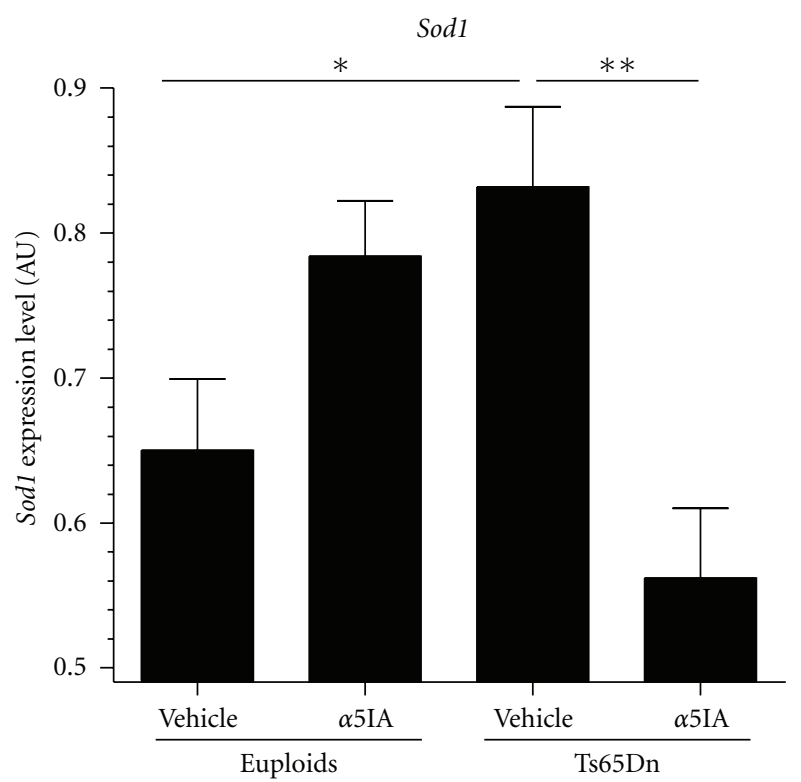

FIGURE 4: QPCR expression level of Sod1 gene in euploid and Ts65Dn mice after chronic treatment with vehicle or $\alpha 5$ IA. ${ }^{*} P<$ $.05,{ }^{*} P<.01$, and two-way ANOVA with Fisher's post hoc comparisons.

treated Ts65Dn mice $\left(F_{1,17}=14.43 ; P<.01\right)$. Thus, Sod1 expression in Ts65Dn mice under $\alpha 5$ IA treatment was similar to vehicle-treated euploid mice, suggesting that chronic treatment with $\alpha 5$ IA allowed Sod 1 to return to a physiological level of expression in the hippocampus of Ts65Dn mice. 
3.3. Gene Expression Changes of IEGs Genes after $\alpha 5 I A$ Treatment. PCA on the 16 IEGs expressed in the hippocampus showed a total separation between euploid and Ts65Dn mice but also a partial segregation as a function of treatment (Figure 5). Two-way ANOVA on these 16 IEGs revealed an effect of genotype (euploid versus Ts65Dn) on 5 genes ( $B d n f$, Cox2, Homer1, RGS2, and Arc), an effect of treatment (vehicle versus $\alpha 5 \mathrm{IA} 5 \mathrm{mg} / \mathrm{kg}$ ) on 3 genes (c-Fos, Egr2, and Bdnf), and a genotype by treatment interaction effect on one gene $(B d n f)$. Among the differentially expressed genes, there was a significant enrichment of IEGs modulated by genotype and treatment (chi-square: genotype $P<.001$, chi-square: treatment $P<.05$ ) supporting an effect of genotype and treatment on IEGs expression levels (Table 1).

We selected 4 IEGs classically described as expressed during behavioral stimulation: Arc, Homer1, c-Fos, and EGR2 for validation using QPCR analysis on 21 samples (5-6 per group), 8 of which were not used in the microarray experiments (Figure 6). Two-way ANOVA analysis with within-subjects design on IEGs expression showed genotype $\left(F_{1,16}=7.90 ; P<.05\right)$, treatment $\left(F_{1,16}=11.72 ; P<.01\right)$, and gene $\left(F_{4,64}=91.66 ; P<.001\right)$ effects. The expression level of IEGs was increased in euploid mice (treated or not with $\alpha 5$ IA) as compared to Ts65Dn mice (Fisher's post hoc test: $P=.012$ ). The mean expression ratio Ts65Dn/euploid for these 4 genes was found to be 0.82 . In contrast, $\alpha 5$ IA-treated mice (euploid or Ts65Dn) showed higher levels of expression of IEGs relative to vehicle-treated mice (Fisher's post hoc test: $P=.0034)$. The mean expression ratio $\alpha 5 \mathrm{IA} /$ vehicle for these genes was 1.29.

Individual IEGs expression levels were normalized against the vehicle-treated euploid mice value that corresponds to the physiological level of expression. In euploid mice, all IEGs increased after $\alpha$ IIA treatment. This increase was statistically significant for $c$-Fos and Arc genes (one sample $t$-test: $t_{4}=6.44, P=.003$, and $t_{4}=2.89 ; P=$ .04 , resp.). In Ts65Dn mice, the basal level of expression of IEGs was lower as compared to euploids. C-Fos and Egr2 expression was drastically reduced (one sample $t$-test: $t_{3}=3.62, P=.036$, and $t_{3}=20.38 ; P=.0003$, resp.). Interestingly, IEGs expression profiles were normalized to euploid mice levels after $\alpha 5$ IA treatment. In addition, we found inverse correlations between the expression levels of Fos, Egr2, Homer1, and Arc deduced from QPCR and the mean distance travelled during the first three training sessions of the MWM $(-0.645<r<-0.494$; Figure 7$)$.

\section{Discussion}

We have previously shown that treatment with $\alpha 5$ IA alleviates learning and memory deficits of Ts65Dn mice [35] We also demonstrated that $\alpha 5$ IA increased the expression of the IEG product Fos in specific brain regions involved in learning and memory following cognitive stimulation. Importantly, following $\alpha$ IA administration, both genotypes were observed to display significant and comparable Fos induction. This potentiation of brain activity might therefore be the substratum of the general promnesiant effects of $\alpha 5$ IA

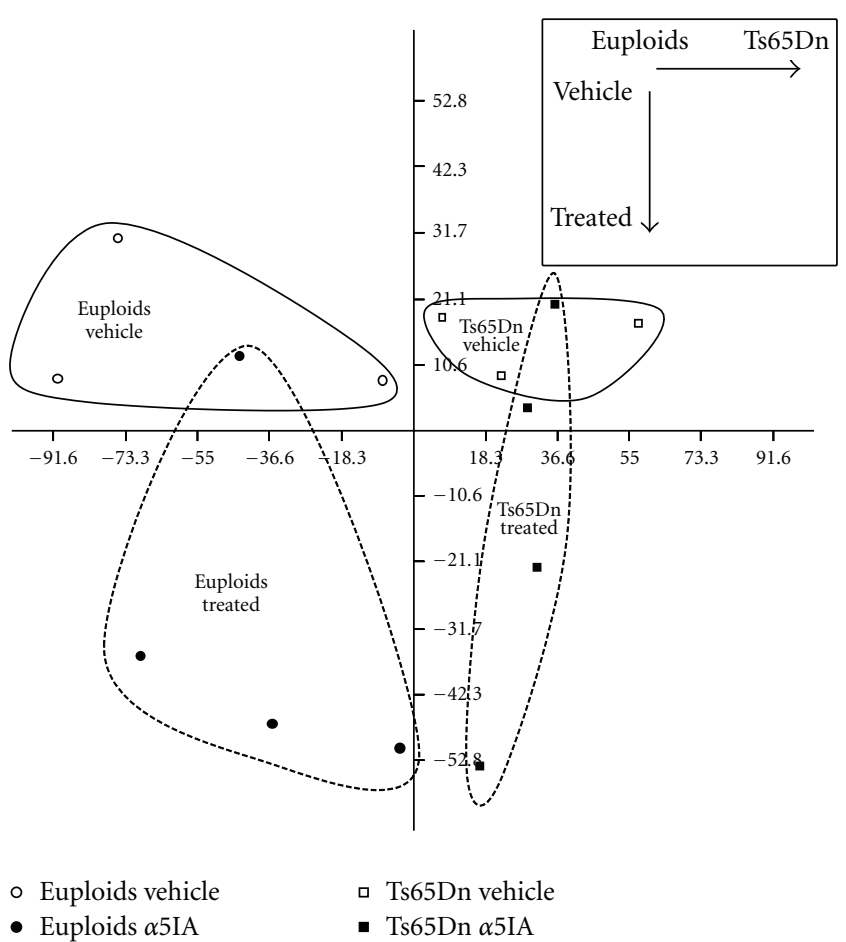

FIGURE 5: PCA on IEGs expression measured on microarrays. The first principal component fully discriminated euploid and Ts65Dn mice. The second principal component partially discriminated vehicle- and $\alpha 5$ IA-treated mice.

independently of the disease status. In order to gain more insight into mechanisms of the general promnesiant effects as well as the rescuing effects in Ts65Dn mice, we studied gene expression regulation networks in mice trained in the MWM task. During this continuous training episode, mice received daily injections of $\alpha 5 \mathrm{IA}$ ( $5 \mathrm{mg} / \mathrm{kg}$ ) for a total of 12 days. Gene expression was then measured using DNA microarrays from hippocampal RNA extracts obtained $30 \mathrm{~min}$ after the last training session.

\subsection{Hippocampal Gene Expression Networks Regulated by 25 IA in Control Euploid Mice}

4.1.1. Effects on HSA21 Genes. Microarray and QPCR analysis on the expression of genes from the region of mouse chromosome 16 which is triplicated in Ts65Dn mice and is orthologous to human chromosome 21 (HSA21) genes did not reveal any effect of chronic treatment with $\alpha 5$ IA. These results suggest that genes from this triplicated region are not interfering with the activity of $\alpha 5 \mathrm{IA}$ and hence do not modify the $\alpha 5$ subunit-containing GABA-A-benzodiazepine receptors or their signaling pathways.

\subsubsection{Effects on IEGs Expression during Memory Processes.} Following memory stimulation, chronic treatment with $\alpha 5$ IA enhanced IEG activation in euploid mice. It is likely that higher IEG transcripts following $\alpha$ IA treatment will result in an increase of IEG protein products (e.g., Fos protein) 


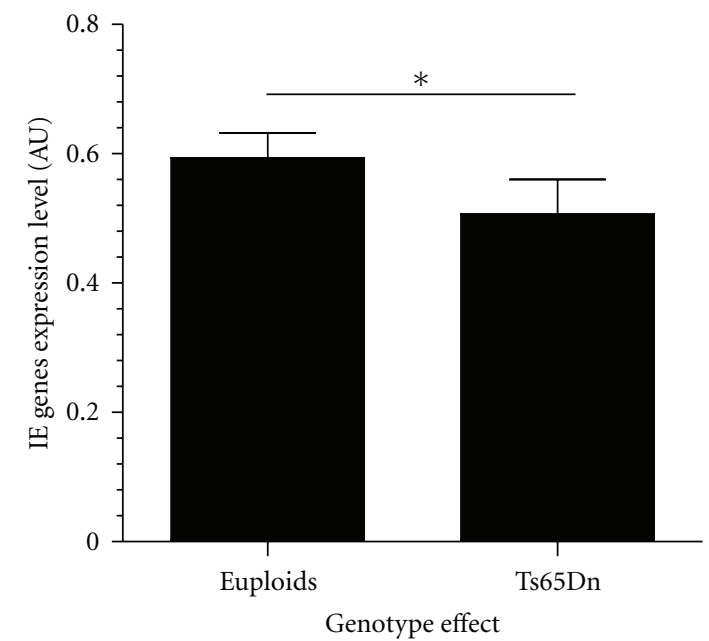

(a)

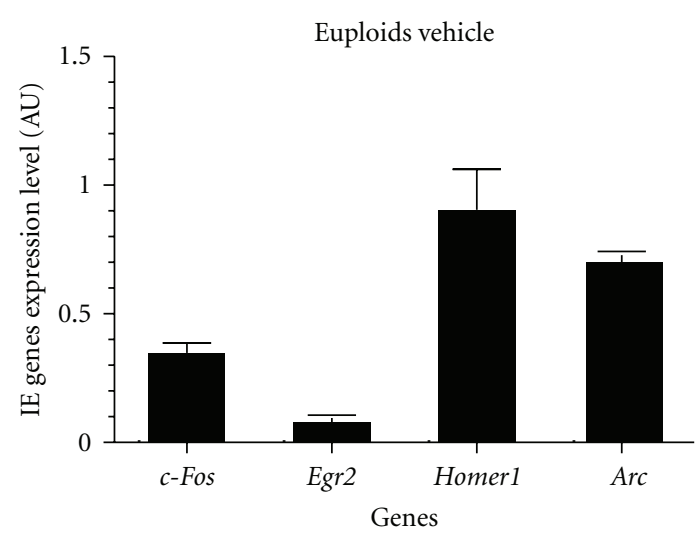

Ts65Dn vehicle

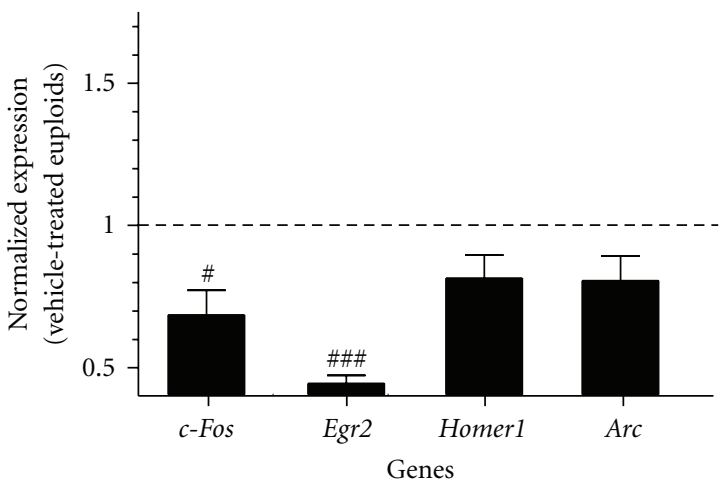

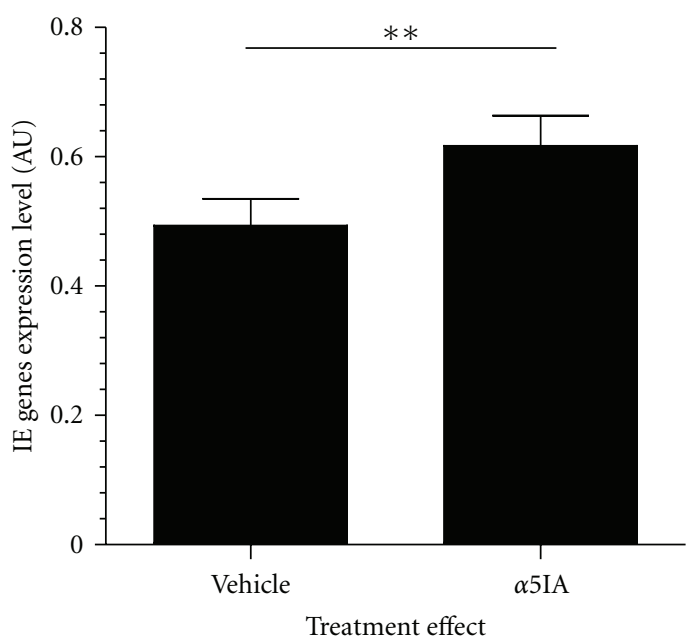

(b)

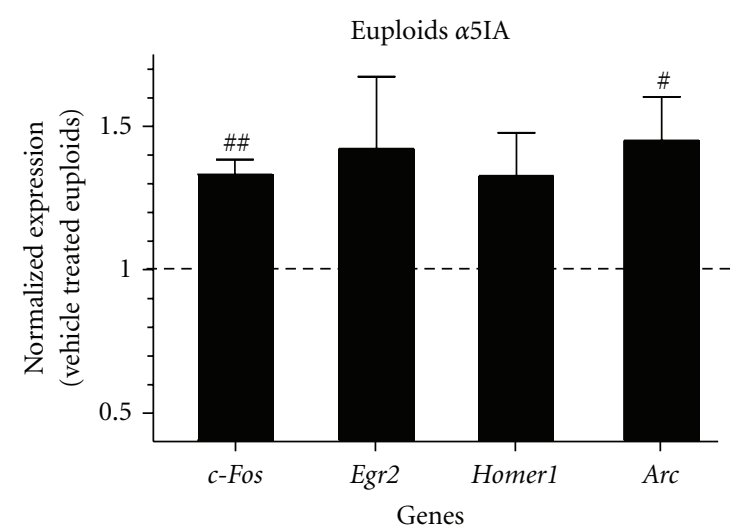

Ts65Dn $\alpha 5$ IA

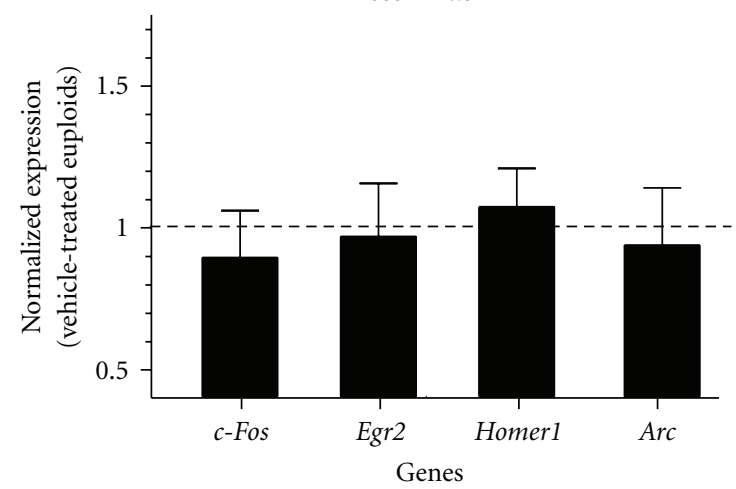

(c)

FIGURE 6: QPCR expression level of selected IEGs. (a) Mean cumulated expression levels of five selected IEGs in euploid and Ts65Dn mice; (b) effect of $\alpha$ IIA treatment on the mean level of expression of five selected IEGs; (c) expression of $c$-Fos, Egr2, Bdnf, Homer-1, and Arc in the four genotype and treatment experimental groups. ${ }^{*} P<.05$, two-way ANOVA with Fisher's post hoc comparisons; ${ }^{\#} P<.05$, ${ }^{\# \#} P<.001$, and one-sample $t$-test.

as confirmed in our previous study [35], while without behavioral stimulation, $\alpha 5$ IA did not increase the IEG product Fos (data not shown). These results suggest a state dependency (cognitive stimulation) of the effects of $\alpha 5$ IA on IEG expression. IEG expression regulation after $\alpha 5$ IA treatment following behavioral stimulation could be a contributing factor for both the general promnesiant activity of $\alpha 5 \mathrm{IA}$ and its rescuing effect in Ts65Dn mice alongside signaling cascades that are critical for memory consolidation and cognition. 


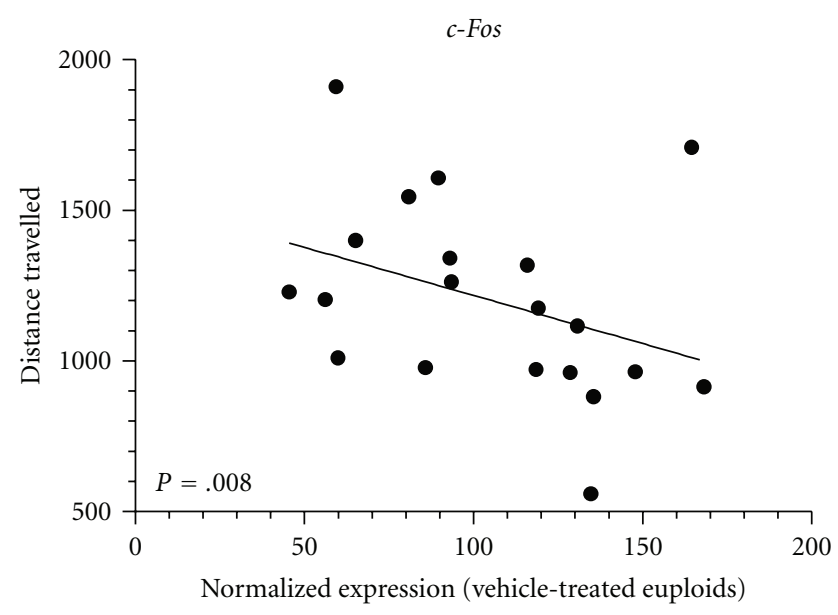

(a)

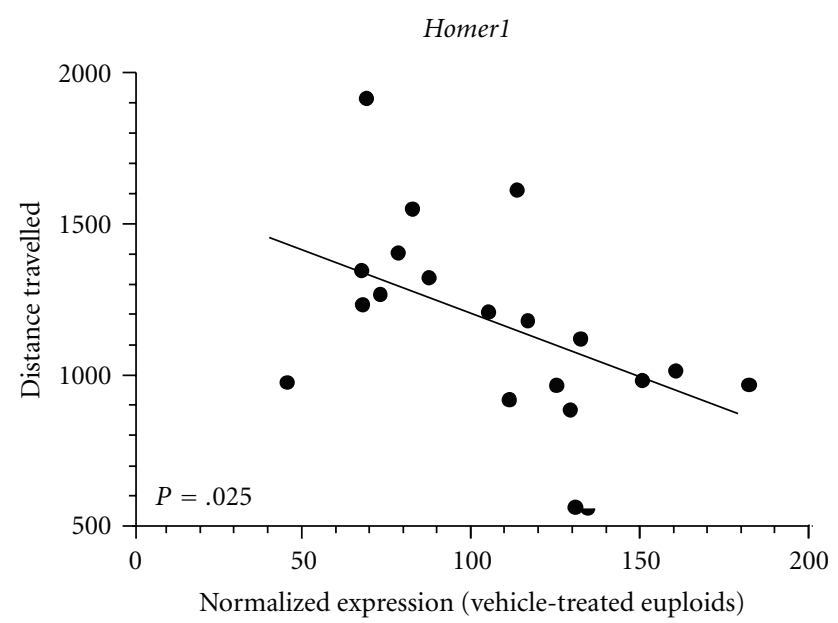

(c)

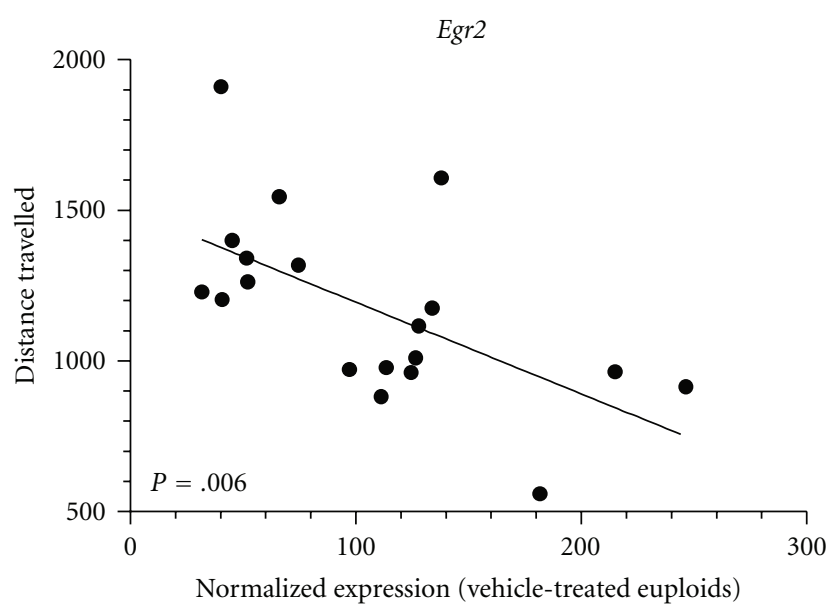

(b)

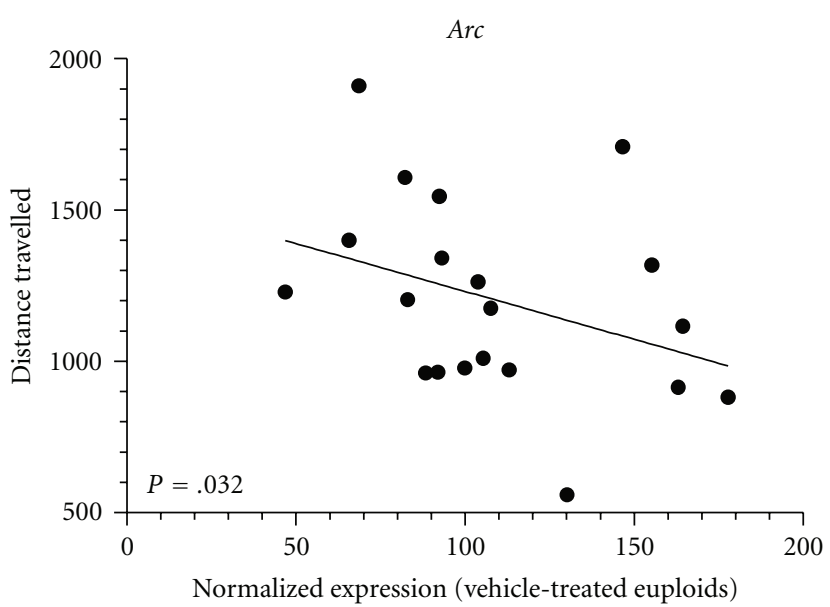

(d)

FIGURE 7: Correlation between IEGs expression levels and behavioral performances. Expression levels of IEGs were negatively correlated to the mean distance travelled during MWM testing $(-0.645<r<-0.494$, Pearson correlation) underlining a tight relationship between learning proficiency and IEGs activation.

\subsection{Hippocampal Gene Expression Networks Regulated by 25 IA in Ts65Dn Mice}

\subsubsection{Effects on HSA21 Genes}

Gene Expression Differences between Ts65Dn and Euploid Hippocampi. Of the 108 HSA21 genes present on the microarray and expressed in the hippocampus, only 6 were differentially expressed between Ts65Dn and euploid mice: Gart, Ifnar-2, Kcnj6, Itsn1, Hlcs and, Sod1. To our knowledge, this is the first time that gene expression profiles have been established in the hippocampus of adult Ts65Dn mice. We focused our attention on the Sod1 gene which has been extensively studied in DS and confirmed our results using QPCR. LTP deficits observed in Ts65Dn [8] could be due to overexpression and thus increased activity of Sod1 in the hippocampus since overexpression of Sod1 gene in transgenic mice is sufficient to impair LTP [40]. Increased level of Sod1 has also been shown to enhance the sensitivity to degeneration and apoptosis leading to a reduction of hippocampal neuronal progenitors [41]. This could explain enrichment for numerous GO categories related to neurogenesis among the genes differentially expressed between Ts65Dn and euploids. Such effects on neurogenesis-related genes may contribute to the memory deficits observed in Ts65Dn mice [42] and also in humans with memory dysfunction [43]. Since Sod1 and IEGs expressions are inversely modulated in Ts65Dn mice as compared to euploids before and after treatment, it could also be speculated that Sod1 and IEGs are functionally regulated, IEGs inhibiting Sod1 expression and conversely increased Sod1 levels decreasing IEGs after behavioral stimulation.

Chronic Treatment with $\alpha 5 I A$ Restores the Expression of Sod1 in Ts65Dn Mice to Normal Physiological Levels. Chronic 
treatment of Ts65Dn mice with $\alpha 5$ IA normalized the level of expression of Sod1 in the hippocampus. Although the exact mechanisms responsible for this effect are unclear, we can postulate that chronic treatment with $\alpha$ IA could alleviate cognitive deficits at least partly through the normalization of Sod1 expression in the hippocampus. Since Sod1 overexpression impairs hippocampal neurogenesis and long-term synaptic plasticity, $\alpha 5$ IA could reverse these deleterious effects by decreasing the expression levels of Sod1. Stimulating or restoring neurogenesis might thus participate in the recovery of cognitive functions of Ts65Dn mice, as suggested also by enrichment of GO categories associated with proliferation and cell death among differentially expressed genes.

\subsubsection{Effects on IEGs Expression}

Reduction of IEG Activation Pattern in Ts65Dn Mice. It is known that IEGs play a key role in learning and memory mechanisms which are deficient in Ts65Dn mice. Indeed, long-term memory requires activation of specific IEGs [44]. Neuronal IEGs mostly code for transcription factors, growth factors, cytoskeletal proteins, metabolic enzymes, or proteins involved in signal transduction [45]. Memorization of new information requires the establishment of a pattern of IEGs expression. It has been shown that age-related memory deficits in rats result in an overall decrease in the expression of IEG in the hippocampus, particularly Homer-1, Arc, and different members of EGR family [46]. After behavioral stimulation in the MWM task, we found, using microarray and QPCR, a significant reduction in the overall level of IEGs in Ts65Dn mice as compared to euploids. This reduction was observed in particular for c-Fos and Egr2. For Homer-1, and Arc, decreased expression in Ts65Dn mice was just below the level of significance. This could be due to differences in the kinetics of waves of expression of these particular IEGs [44].

Chronic Treatment of Ts65Dn Mice with $\alpha 5$ IA Restores Normal IEG Activation Pattern. Ts65Dn mice treated chronically with $\alpha 5$ IA showed normalized levels of activation of IEG following memory stimulation, particularly c-Fos, Egr2, Homer-1 and Arc that could be related to the recovery of MWM performance deficits observed in the present study and demonstrated previously [35]. Normalization of the activation profile of IEG following behavioral stimulation could thus be responsible for the rescuing effects of $\alpha 5 \mathrm{IA}$ observed in Ts65Dn mice. The close relationship between IEGs expression levels and cognitive performances was indeed suggested by the significant inverse correlations found between the expression levels of Fos, Egr2, Homer1 and Arc and performances in the MWM task. In addition, $\alpha 5 \mathrm{IA}$ treatment was shown to restore Ts65Dn mice performances in the MWM task and to normalize the expression levels of c-Fos, Egr2, Homer-1, and Arc.
4.3. General Promnesiant and Rescuing Effects of $\alpha 5 I A$. The general $\alpha$ IA promnesiant effect observed in euploid and Ts65Dn mice could be explained by the acute pharmacological action of the drug directly on $\alpha 5$ GABAA-benzodiazepine receptors. Indeed, $\alpha 5$ inverse agonists decrease GABAergic transmission and promote the excitability of postsynaptic neurons in rodents [28-32]. The previously described increase of Fos protein immunoreactivity after short-term memory stimulation combined with $\alpha 5$ IA acute treatment could thus be the consequence of immediate release of GABA inhibition [35]. Following repetitive cognitive stimulations as in the MWM task that involves hippocampus-dependent memory, we evidenced IEGs activation deficits in the hippocampus of Ts65Dn mice that were rescued after chronic $\alpha 5$ IA treatment. However, we cannot exclude that a single injection of $\alpha$ IA would have a similar effect on IEGs expression levels. It thus appears that the rescuing effects of $\alpha 5$ IA on long-term memories are more likely the consequence of hippocampal IEGs expression normalization than the long term effect of repetitive GABAergic modulations. In addition, as mentioned above, it is likely that the normalization of Sod 1 overexpression by $\alpha 5$ IA is also important to promote cognitive rescuing.

\section{Conclusions}

We have identified genomic changes related to chronic treatment with $\alpha 5 \mathrm{IA}$, an $\alpha 5$-selective GABA-A receptor inverse agonist. Under physiological conditions in which $\alpha 5$ IA has been shown to be promnesiant, increase of IEGs activation has been observed and in particular of $c$-Fos and Arc genes. This increase of activation could allow a more efficient storage of information during memory process.

Under pathological conditions such as DS in which deficits in learning and memory have been described, we were able to demonstrate an effect of chronic treatment with $\alpha 5$ IA at the level of expression of different genes in Ts65Dn mice. Indeed, chronic administration of $\alpha 5 \mathrm{IA}$ restored a normal level of Sod1 expression which is involved in hippocampal neurogenesis and LTP. In addition, chronic treatment with $\alpha$ IA normalized the pattern of IEGs activation that is deficient in Ts65Dn mice. These genomic changes observed after chronic treatment with $\alpha$ IA could be responsible for the restoration of learning and memory functions in Ts65Dn mice.

\section{Acknowledgments}

The authors wish to thank the Fondation AMIPI-Bernard Vendre, the AnEUploidy program (LSHG-CT-2006-037627), and the Fondation Jérôme Lejeune for their financial support. They are grateful to Dr. I Rivals for helpful discussions on statistics and to zoo technicians from UPS 44(Orléans) for providing animal care. 


\section{References}

[1] T. Hassold, M. Abruzzo, K. Adkins et al., "Human aneuploidy: incidence, origin and etiology," Environmental and Molecular Mutagenesis, vol. 28, no. 3, pp. 167-175, 1996.

[2] R. H. Reeves and C. C. Garner, "A year of unprecedented progress in Down syndrome basic research," Mental Retardation and Developmental Disabilities Research Reviews, vol. 13, no. 3, pp. 215-220, 2007.

[3] F. K. Wiseman, K. A. Alford, V. L. J. Tybulewicz, and E. M. C. Fisher, "Down syndrome-recent progress and future prospects," Human Molecular Genetics, vol. 18, no. R1, pp. R75-R83, 2009.

[4] R. H. Reeves, N. G. Irving, T. H. Moran et al., "A mouse model for Down syndrome exhibits learning and behaviour deficits," Nature Genetics, vol. 11, no. 2, pp. 177-184, 1995.

[5] Z. Seregaza, P. L. Roubertoux, M. Jamon, and B. SoumireuMourat, "Mouse models of cognitive disorders in trisomy 21: a review," Behavior Genetics, vol. 36, no. 3, pp. 387-404, 2006.

[6] R. J. Siarey, J. Stoll, S. I. Rapoport, and Z. Galdzicki, "Altered long-term potentiation in the young and old Ts65Dn mouse, a model for Down syndrome," Neuropharmacology, vol. 36, no. 11-12, pp. 1549-1554, 1997.

[7] T. K. Best, R. J. Siarey, and Z. Galdzicki, “Ts65Dn, a mouse model of Down syndrome, exhibits increased GABA Binduced potassium current," Journal of Neurophysiology, vol. 97, no. 1, pp. 892-900, 2007.

[8] A. M. Kleschevnicov, P. V. Belichenko, A. J. Villar, C. J. Epstein, R. C. Malenka, and W. C. Mobley, "Hippocampal long-term potentiation suppressed by increased inhibition in the Ts65Dn mouse, a genetic model of Down syndrome," Journal of Neuroscience, vol. 24, no. 37, pp. 8153-8160, 2004.

[9] F. Fernandez, W. Morishita, E. Zuniga et al., "Pharmacotherapy for cognitive impairment in a mouse model of Down syndrome," Nature Neuroscience, vol. 10, no. 4, pp. 411-413, 2007.

[10] N. Rueda, J. Florez, and C. Martinez-Cue, "Chronic pentylenetetrazole but not donepezil treatment rescues spatial cognition in Ts65Dn mice, a model for Down syndrome," Neuroscience Letters, vol. 433, no. 1, pp. 22-27, 2008.

[11] A. K. Evans and C. A. Lowry, "Pharmacology of the betacarboline FG-7142, a partial inverse agonist at the benzodiazepine allosteric site of the GABAA receptor: neurochemical, neurophysiological, and behavioral effects," CNS Drug Reviews, vol. 13, no. 4, pp. 475-501, 2007.

[12] R. K. McNamara and R. W. Skelton, "Benzodiazepine receptor antagonists flumazenil and CGS 8216 and inverse- agonist $\beta$ CCM enhance spatial learning in the rat: dissociation from anxiogenic actions," Psychobiology, vol. 21, no. 2, pp. 101-108, 1993.

[13] P. Venault and G. Chapouthier, "From the behavioral pharmacology of beta-carbolines to seizures, anxiety, and memory," TheScientificWorldJournal, vol. 7, pp. 204-223, 2007.

[14] P. Venault, G. Chapouthier, and L. P. De Carvalho, "Benzodiazepine impairs and beta-carboline enhances performance in learning and memory tasks," Nature, vol. 321, no. 6073, pp. 864-866, 1986.

[15] R. Dorow, R. Horowski, and G. Paschelke, "Severe anxiety induced by FG 7142, a beta-carboline ligand for benzodiazepine receptors," The Lancet, vol. 2, no. 8341, pp. 98-99, 1983.

[16] Y. Clement and G. Chapouthier, "Biological bases of anxiety," Neuroscience and Biobehavioral Reviews, vol. 22, no. 5, pp. 623-633, 1998.
[17] C. D'Hulst, J. R. Atack, and R. F. Kooy, "The complexity of the GABA(A) receptor shapes unique pharmacological profiles," Drug Discovery Today, vol. 14, no. 17-18, pp. 866-875, 2009.

[18] J. M. Fritschy and H. Mohler, "GABAA-receptor heterogeneity in the adult rat brain: differential regional and cellular distribution of seven major subunits," Journal of Comparative Neurology, vol. 359, no. 1, pp. 154-194, 1995.

[19] S. Pirker, C. Schwarzer, A. Wieselthaler, W. Sieghart, and G. Sperk, "GABA(A) receptors: immunocytochemical distribution of 13 subunits in the adult rat brain," Neuroscience, vol. 101, no. 4, pp. 815-850, 2000.

[20] W. Wisden, D. J. Laurie, H. Monyer, and P. H. Seeburg, "The distribution of 13 GABAA receptor subunit mRNAs in the rat brain. I. Telencephalon, diencephalon, mesencephalon," Journal of Neuroscience, vol. 12, no. 3, pp. 1040-1062, 1992.

[21] C. Sur, L. Fresu, O. Howell, R. M. McKernan, and J. R. Atack, "Autoradiographic localization of alpha5 subunit-containing GABAA receptors in rat brain," Brain Research, vol. 822, no. 1-2, pp. 265-270, 1999.

[22] C. Sur, K. Quirk, D. Dewar, J. Atack, and R. McKernan, "Rat and human hippocampal alpha5 subunit-containing gammaaminobutyric acidA receptors have alpha5 beta3 gamma2 pharmacological characteristics," Molecular Pharmacology, vol. 54, no. 5, pp. 928-933, 1998.

[23] L. Nadel, "Down's syndrome: a genetic disorder in biobehavioral perspective," Genes, Brain and Behavior, vol. 2, no. 3, pp. 156-166, 2003.

[24] B. F. Pennington, J. Moon, J. Edgin, J. Stedron, and L. Nadel, "The neuropsychology of Down syndrome: evidence for hippocampal dysfunction," Child Development, vol. 74, no. 1, pp. 75-93, 2003.

[25] N. Collinson, F. M. Kuenzi, W. Jarolimek et al., "Enhanced learning and memory and altered GABAergic synaptic transmission in mice lacking the alpha 5 subunit of the GABAA receptor," Journal of Neuroscience, vol. 22, no. 13, pp. 55725580, 2002.

[26] F. Crestani, R. Keist, J. M. Fritschy et al., "Trace fear conditioning involves hippocampal alpha5 GABA(A) receptors," Proceedings of the National Academy of Sciences of the United States of America, vol. 99, no. 13, pp. 8980-8985, 2002.

[27] B. K. Yee, J. Hauser, V. V. Dolgov et al., "GABAA receptors containing the alpha5 subunit mediate the trace effect in aversive and appetitive conditioning and extinction of conditioned fear," European Journal of Neuroscience, vol. 20, no. 7, pp. 1928-1936, 2004.

[28] J. R. Atack, "Preclinical and clinical pharmacology of the GABA(A) receptor alpha5 subtype-selective inverse agonist alpha5IA," Pharmacology and Therapeutics, vol. 125, no. 1, pp. 11-26, 2010.

[29] J. R. Atack, P. J. Bayley, G. R. Seabrook, K. A. Wafford, R. M. McKernan, and G. R. Dawson, "L-655,708 enhances cognition in rats but is not proconvulsant at a dose selective for alpha5containing GABAA receptors," Neuropharmacology, vol. 51, no. 6, pp. 1023-1029, 2006.

[30] T. M. Ballard, F. Knoflach, E. Prinssen et al., "RO4938581, a novel cognitive enhancer acting at GABA(A) alpha5 subunitcontaining receptors," Psychopharmacology, vol. 202, no. 1-3, pp. 207-223, 2009.

[31] N. Collinson, J. R. Atack, P. Laughton, G. R. Dawson, and D. N. Stephens, "An inverse agonist selective for alpha5 subunit-containing GABAA receptors improves encoding and recall but not consolidation in the Morris water maze," Psychopharmacology, vol. 188, no. 4, pp. 619-628, 2006. 
[32] N. Collinson, J. R. Atack, P. Laughton, G. R. Dawson, and D. N. Stephens, "An inverse agonist selective for alpha5 subunitcontaining GABAA receptors enhances cognition," Journal of Pharmacology and Experimental Therapeutics, vol. 316, no. 3, pp. 1335-1345, 2006.

[33] M. S. Chambers, J. R. Atack, R. W. Carling et al., "An orally bioavailable, functionally selective inverse agonist at the benzodiazepine site of GABAA alpha5 receptors with cognition enhancing properties," Journal of Medicinal Chemistry, vol. 47, no. 24, pp. 5829-5832, 2004.

[34] F. Sternfeld, R. W. Carling, R. A. Jelley et al., "Selective, orally active gamma-aminobutyric acidA alpha5 receptor inverse agonists as cognition enhancers," Journal of Medicinal Chemistry, vol. 47, no. 9, pp. 2176-2179, 2004.

[35] J. Braudeau, B. Delatour, A. Duchon et al., "Specific targeting of the GABA-A receptor \{alpha\} 5 subtype by a selective inverse agonist restores cognitive deficits in Down syndrome mice," Journal of Psychopharmacology, vol. 25, no. 8, pp. 10301042, 2004.

[36] S. M. Hoelter, C. Dalke, M. Kallnik et al., "'Sighted C3H' mice- - a tool for analysing the influence of vision on mouse behaviour?" Frontiers in Bioscience, vol. 13, pp. 5810-5823, 2008.

[37] A. C. S. Costa, M. R. Stasko, C. Schmidt, and M. T. Davisson, "Behavioral validation of the Ts65Dn mouse model for Down syndrome of a genetic background free of the retinal degeneration mutation Pde6b(rd1)," Behavioural Brain Research, vol. 206, no. 1, pp. 52-62, 2010.

[38] A. Sawa, "Alteration of gene expression in Down's syndrome (DS) brains: its significance in neurodegeneration," Journal of Neural Transmission, Supplementa, no. 61, pp. 361-371, 2001.

[39] R. C. Iannello, P. J. Crack, J. B. De Haan, and I. Kola, "Oxidative stress and neural dysfunction in Down syndrome," Journal of Neural Transmission, Supplementa, no. 57, pp. 257267, 1999.

[40] E. Gahtan, J. M. Auerbach, Y. Groner, and M. Segal, "Reversible impairment of long-term potentiation in transgenic Cu/Zn-SOD mice," European Journal of Neuroscience, vol. 10, no. 2, pp. 538-544, 1998.

[41] Z. Liu and L. J. Martin, "The adult neural stem and progenitor cell niche is altered in amyotrophic lateral sclerosis mouse brain," Journal of Comparative Neurology, vol. 497, no. 3, pp. 468-488, 2006.

[42] S. Clark, J. Schwalbe, M. R. Stasko, P. J. Yarowsky, and A. C. S. Costa, "Fluoxetine rescues deficient neurogenesis in hippocampus of the Ts65Dn mouse model for Down syndrome," Experimental Neurology, vol. 200, no. 1, pp. 256261, 2006.

[43] R. Coras, F. A. Siebzehnrubl, E. Pauli et al., "Low proliferation and differentiation capacities of adult hippocampal stem cells correlate with memory dysfunction in humans," Brain, vol. 133, no. 11, pp. 3359-3372, 2010.

[44] T. Miyashita, S. Kubik, G. Lewandowski, and J. F. Guzowski, "Networks of neurons, networks of genes: an integrated view of memory consolidation," Neurobiology of Learning and Memory, vol. 89, no. 3, pp. 269-284, 2008.

[45] A. Lanahan and P. Worley, "Immediate-early genes and synaptic function," Neurobiology of Learning and Memory, vol. 70, no. 1-2, pp. 37-43, 1998.

[46] W. B. Rowe, E. M. Blalock, K. C. Chen et al., "Hippocampal expression analyses reveal selective association of immediateearly, neuroenergetic, and myelinogenic pathways with cognitive impairment in aged rats," Journal of Neuroscience, vol. 27, no. 12 , pp. 3098-3110, 2007. 

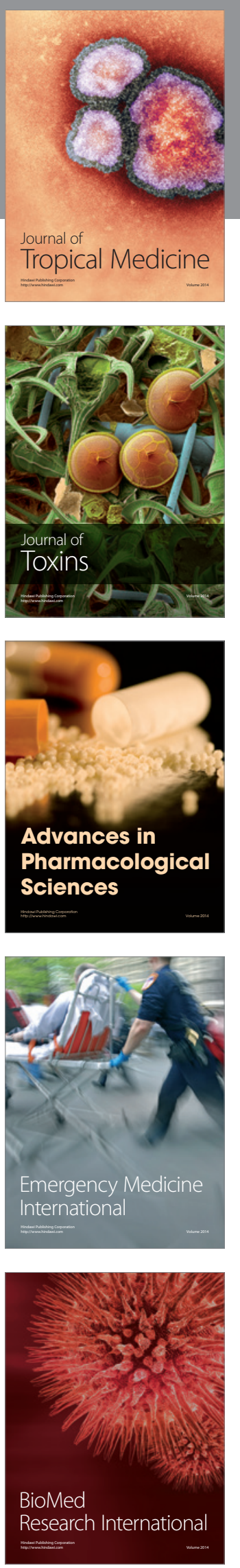
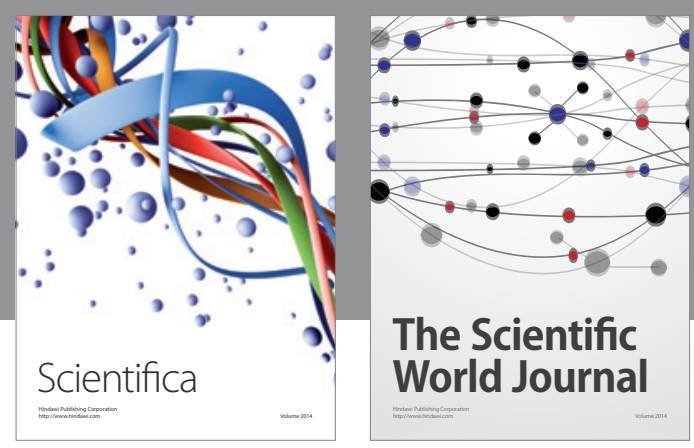

The Scientific World Journal
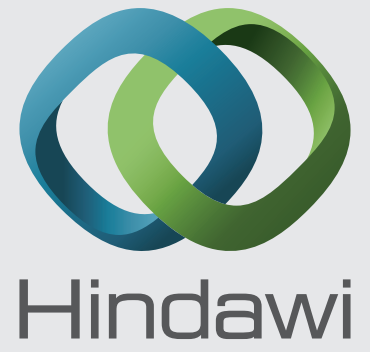

Submit your manuscripts at

http://www.hindawi.com
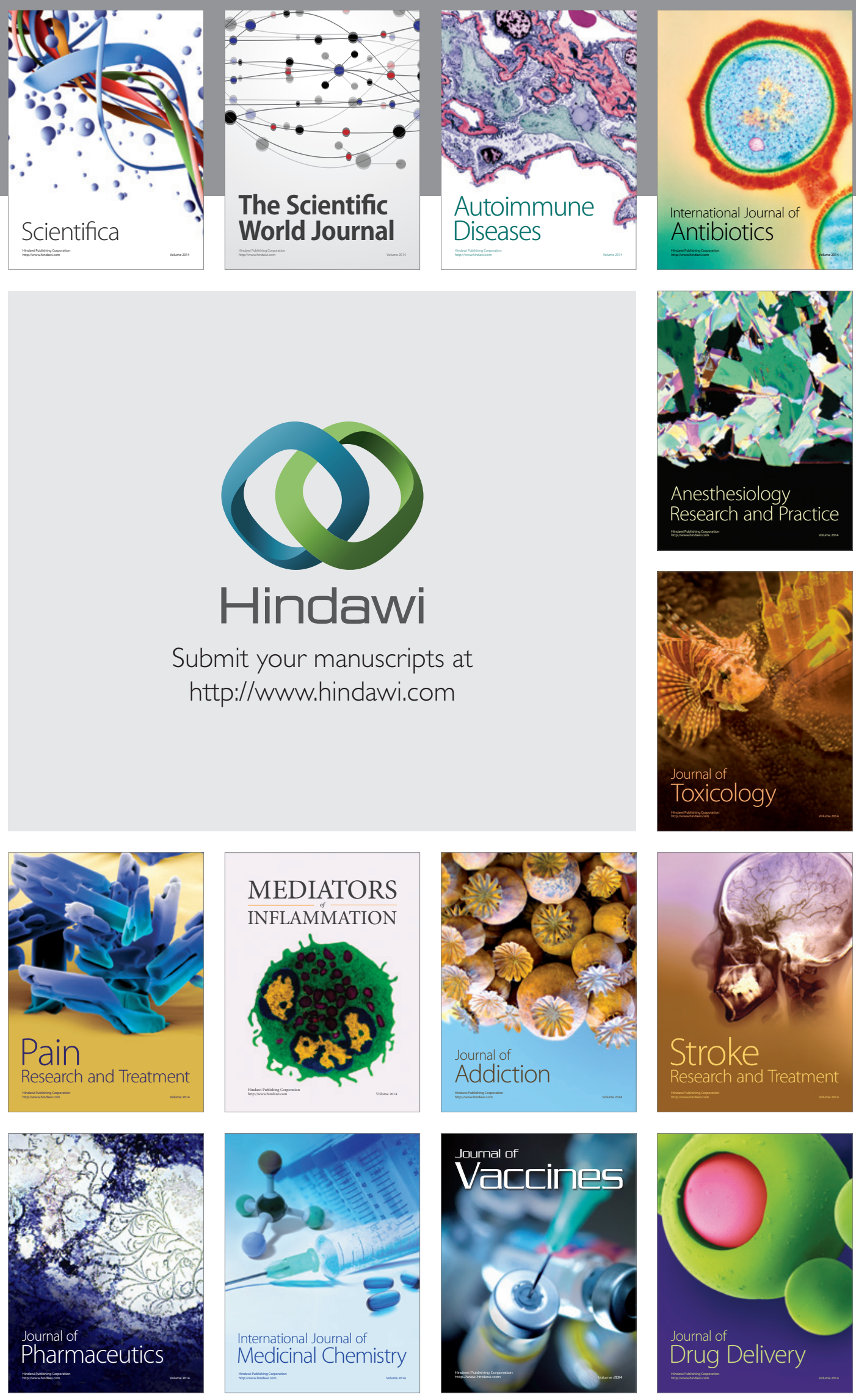